\title{
BMJ Open Health facility structure and maternal characteristics related to essential newborn care in Brazil: a cross-sectional study
}

\author{
Maria Alexsandra Silva Menezes, ${ }^{1}$ Ricardo Gurgel, ${ }^{1}$ \\ Sonia Duarte Azevedo Bittencourt, ${ }^{2}$ Vanessa Eufrazino Pacheco, ${ }^{3}$ \\ Rosana Cipolotti, ${ }^{1}$ Maria do Carmo Leal ${ }^{2}$
}

To cite: Menezes MAS, Gurgel R, Bittencourt SDA, et al. Health facility structure and maternal characteristics related to essential newborn care in Brazil: a crosssectional study. BMJ Open 2018;8:e21431. doi:10.1136/ bmjopen-2017-021431

- Prepublication history for this paper is available online. To view these files, please visit the journal online (http://dx.doi. org/10.1136/bmjopen-2017021431).

Received 28 December 2017 Revised 10 October 2018 Accepted 2 November 2018

Check for updates

(c) Author(s) (or their employer(s)) 2018. Re-use permitted under CC BY-NC. No commercial re-use. See rights and permissions. Published by BMJ.

${ }^{1}$ Postgraduate Programme in Health Science, Sergipe Federal University, Aracaju, Brazil ${ }^{2}$ Department of Epidemiology and Quantitative Methods in Health, National School of Public Health (ENSP/FIOCRUZ), Rio de Janeiro, Brazil

${ }^{3}$ Postgraduate Programme in Epidemiology and Public Health, National School of Public Health (ENSP/FIOCRUZ), Rio de Janeiro, Brazil

Correspondence to Dr Maria Alexsandra Silva Menezes; alexsandra.mar@hotmail.com

\section{ABSTRACT}

Objectives To assess the use of the WHO's Essential Newborn Care (ENC) programme items and to investigate how the non-use of such technologies associates with the mothers' characteristics and hospital structure.

Design A cross-sectional observational health facility assessment.

Setting This is a secondary analysis of the 'Birth in Brazil' study, a national population-based survey on postnatal women/newborn babies and of 266 publicly and privately funded health facilities (secondary and tertiary level of care).

Participants Data on 23894 postnatal women and their newborn babies were analysed.

Main outcome measures The facility structure was assessed by evaluating the availability of medicines and equipment for perinatal care, a paediatrician on call 24/7, a neonatal intensive care unit (NICU) and kangaroo mother care. The use of each ENC item was assessed according to the health facility structure and the mothers' sociodemographic characteristics.

Results The utilisation of ENC items is low in Brazil. The factors associated with failure in pregnant woman reference were: pregnant adolescents $\left(\mathrm{OR}_{\text {adj }} 1.17 ; 95 \% \mathrm{Cl} 1.06\right.$ to $1.29)$, $\leq 7$ years of schooling $\left(O \mathrm{R}_{\text {adi }} 1.47 ; 95 \% \mathrm{Cl} 1.22\right.$ to 1.78), inadequate antenatal care $\left(0 \mathrm{R}_{\text {adi }} 1.67 ; 95 \% \mathrm{Cl} 1.47\right.$ to 1.89). The non-use of corticosteroids was more frequently associated with the absence of an $\mathrm{NICU}\left(\mathrm{OR}_{\text {adi }} 3.93 ; 95 \% \mathrm{Cl}\right.$ 2.34 to 6,66), inadequate equipment and medicines $\left(\mathrm{OR}_{\text {adi }}\right.$ 2.16; $95 \% \mathrm{Cl} 1.17$ to 4.01). In caesarean deliveries, there was a less frequent use of a partograph $\left(\mathrm{OR}_{\text {adi }} 4,93 ; 95 \% \mathrm{Cl} 3.77\right.$ to 6.46), early skin-to-skin contact $\left(0 \mathrm{R}_{\text {adj }}^{\text {ad }} 3.07 ; 95 \% \mathrm{Cl} 3.37\right.$ to $4.90)$ and breast feeding in the first hour after birth $\left(\mathrm{OR}_{\text {adj }} 2.55\right.$; $95 \% \mathrm{Cl} 2.21$ to 2.96 ).

Conclusions The coverage of ENC technologies use is low throughout Brazil and shows regional differences. We found a positive effect of adequate structure at health facilities on antenatal corticosteroids use and on partograph use during labour. We found a negative effect of caesarean section on early skin-to-skin contact and early breast feeding.

\section{INTRODUCTION}

The reduction of child mortality is a topic of the Sustainable Development Goal 3, that
Strengths and limitations of this study

- Using primary data, we have conveyed a representative nationwide survey.

- Our data are representative for the entire country and reflect regional characteristics and disparities.

- The 'Birth in Brazil' study was conducted in hospitals with $>500$ deliveries per year, representing $80 \%$ of childbirths in the country.

- The study data was based on information provided by women shortly after delivery, by medical records and by managers, rather than on performance observations of the essential care items.

- The cross-sectional nature of the survey data limits our ability to assess causal relationships.

is, to ensure healthy lives and promote wellbeing for all at all ages. ${ }^{1}$ Neonatal mortality accounts for $45 \%$ of all under-five deaths worldwide $^{2}$ and reaches $64 \%$ in Brazil. ${ }^{3}$

Increased coverage and quality improvement of preconception, antenatal, intrapartum and postnatal interventions can avert $71 \%$ of neonatal deaths by 2025 . Interventions around the labour period are the most effective in reducing neonatal mortality. The wider use of effective interventions will prevent 1 million neonatal deaths by $2020 .{ }^{4}$

Almost two decades ago, with a view to reducing neonatal mortality and morbidity, WHO recommended specific care practices outlined in the Essential Newborn Care (ENC) programme. These are strategic actions extended from preconception care through to the postnatal period. ${ }^{5}$ Infant mortality tends to be lower in countries where the coverage of these essential interventions is high. ${ }^{3}$

In Brazil, antenatal care coverage is high (98\% of pregnant women had at least one antenatal care visit and $66.9 \%$ of them had 
more than six antenatal care visits in 2015) and the hospital delivery rate is almost $100 \%$. Nevertheless, neonatal mortality remains high (9.5 deaths per 1000 live births in 2015) ${ }^{6}$ and deaths in first 24 hours of life account for nearly a quarter of all neonatal deaths. ${ }^{7}$ The main reasons are preventable causes, such as complications from preterm birth, sepsis and intrapartum-related asphyxia. ${ }^{8}$ This situation may be linked to economic, social and biological disparities, but may be also linked to the quality of antenatal care, labour and birth assistance.

However, only limited national data are available on public policies, such as antenatal corticosteroid use in managing preterm labour, and on the availability of the kangaroo mother care (KMC) for preterm or low birth weight newborns. ${ }^{3}$ Thus, identifying shortcomings in perinatal care in Brazil is an essential stage in conducting interventions to allocate resources according to where they are needed most and where their effect will be maximised. This is a problem that may also affect other countries with a similar level of socioeconomic development, observable in different places and at different intensities. ${ }^{9}$

This study aims to evaluate the utilisation of certain core technologies for the care of mothers and newborns, as defined in the WHO's Essential Newborn Care programme, and the association between the non-use of these technologies and variables related to hospital structure and the mothers' characteristics.

\section{METHODS}

\section{Design and setting}

This is a cross-sectional observational health facility assessment.

This study is a secondary analysis of the 'Birth in Brazil' study, ${ }^{10}$ a national population-based survey conducted between February 2011 and October 2012, including data on the mothers' pregnancy and delivery, their newborn babies and the structure of the health facilities where the deliveries occurred.

\section{Participants and sample}

The sample size has a power of $80 \%$ to detect adverse outcomes in the order of $3 \%$, and differences of at least $1.5 \%$ among large geographic regions or types of hospital governance (public/private/mixed). Mixed healthcare facility describes care in private hospitals that was paid for by the government's unified healthcare system. ${ }^{10}$ For this study, mixed and public hospitals were analysed together.

For the 'Birth in Brazil' study, we included 90 women who recently delivered (within the last 24 hours) from every health facility. The sample was selected using threestage cluster sampling. The first encompassed hospitals with 500 or more deliveries per year, stratified according to Brazil's five geographical macro-regions (North, Northeast, Southeast, South and Mid-West), location (state capital or not) and type of funding (public and private), according to random sampling. In the second stage of sampling, an inverse sampling method was used to select as many days as were necessary to interview 90 postnatal women in the hospital. ${ }^{11}$ This method, originally proposed by Haldane ${ }^{12}$ to estimate frequencies and proportions, can be defined as a technique to sample as many units (in this case, days) as are needed to observe a prespecified number of successes or, in this case, 90 interviews performed with postnatal women in the hospital. To account for the difference in the number of live births on weekends and on work days, a minimum of seven consecutive days was mandatory and the size of the field team was determined to ensure compliance with this rule. ${ }^{11}$

The number of postnatal women (third stage of the sample) to be selected per day and for every hospital depended on the number of live births, the number of interview shifts and the number of available interviewers per day in the hospital. To ensure a random selection of postnatal women, the survey central office prepared tables containing an ordered list of women to be interviewed according to the number of live births. The ordering of this list was defined by the order of the women's admittance to the hospital. Some additional women were selected to replace those who did not respond. ${ }^{11}$

\section{Data collection}

Data was obtained from two sources: i) interviews were conducted with health facility managers and with postnatal women during hospitalisation within the first 24 hours after birth; ii) the medical records of mothers and newborns were consulted after hospital discharge or death. In the case of prolonged postpartum hospital stays, records were analysed up to the 42nd day of hospitalisation for mothers and up to the 28th day for newborns. In the case of postnatal transfers of mothers and/or newborns, data were obtained from the hospital records of the transfer destination, even when the hospital was not part of the original sample of the study. In the case of refusal or early discharge, the participant was replaced by a new subject selected from the same hospital. A digital photograph of the antenatal notes was taken when available and the relevant data from the notes were converted into electronic form. All field work was conducted by healthcare professionals or healthcare students under the supervision of the research team. Further information about the sample design and data collection are detailed elsewhere. ${ }^{1013}$

\section{Variable definitions}

Following WHO guidelines, ${ }^{5}$ six essential neonatal care variables were investigated: adequate referral of pregnant woman during the antenatal period to a specific health facility for delivery; administration of antenatal corticosteroids when indicated ${ }^{14}$ to women at risk of preterm birth between 24 and 34 weeks' gestation (gestational age was calculated using an algorithm that primarily relied on early ultrasound estimates) ${ }^{15}$; continuous social support (a companion at all times during the mother's hospital stay); use of a partograph during labour; early skin-to-skin 
contact between mother and newborn, while still in the delivery room and breast feeding in the first hour after birth. These data were abstracted from medical records of mothers and newborns and from interviews with postnatal woman.

At the hospitals, the following structure-related variables were investigated, by interviewing the facilities managers: existence of a neonatal intensive care unit (NICU) and use of the KMC, a paediatrician on call 24 hours a day, availability of equipment for the emergency care of mothers (laryngoscope and endotracheal tube, self-inflating bag valve mask and mechanical ventilator) and newborns (laryngoscope and endotracheal tube, self-inflating bag valve mask, suction device, adapter for meconium aspirator, mechanical ventilator and warming device), availability of medicines for mothers and newborns (antihypertensives, anxiolytics/hypnotics, corticosteroids, oxytocics, inhibitors of uterine contractility, coagulants/ haemostatics, magnesium sulfate, surfactant, eye drops for prophylaxis of gonococcal ophthalmia and anti-D immunoglobulin for Rh-negative women) as required by Brazilian law. ${ }^{16}$ For the set of equipment and medicines, a degree of adequacy was calculated by taking affirmative responses as a percentage of the total items investigated. Health facilities were classified as adequate if $80 \%$ or more of the items were available and inadequate if $<80 \%$ were available. Equal weights were attributed to all items studied.

\section{Analytical approach}

The study variables were compared according to the type of funding (public or private), macro-region (North, Northeast, Southeast, South and Mid-West), location (state capital or not), as well as by the mothers' characteristics, such as age (12-19, 20-34 and 35 or more years), schooling (7 or less, $8-10,11-14$ and 15 or more years in school), social class (A or B, C, D or E), sufficient number of antenatal care visits ( 4 or more visits=adequate; fewer than $4=$ inadequate) and delivery route (vaginal or caesarean section). Women who gave birth in public or mixed healthcare facilities and who were not covered by private health insurance plans were classified as receiving public healthcare at childbirth. Women covered by a private health insurance plan and women who gave birth in private hospitals, regardless of coverage by a health insurance plan, were classified as receiving private healthcare at childbirth.

In Brazil, the organisation responsible for the demographic census Instituto Brasileiro de Geografia e Estatística (IBGE) uses a particular indicator, which is a proxy wealth index. This index considers the schooling of the interviewee and the access to some specific public services and goods that the interviewee possesses at the time of the interview. The individual is classified according to socioeconomic criteria into the following classes: A $\rightarrow 45$ points; $\mathrm{B} 1-$ from 38 to 44 points; B2from 29 to 37 points; C1-from 23 to 28 points; C2-from 17 to 27 points; D-E-from 0 to 16 points. For this work, classes A, B1 and B2 were grouped as class A and B, and classes C1 and C2 were grouped as class C. Classes D and E remained as in the original. ${ }^{17}$

The deliveries included in this study had 'early skin-toskin contact'; few missing cases were reported for 'reference to health facility', 'continuous social support' and 'breast feeding in first hour of birth'. The total 'antenatal corticosteroids used appropriately' were at risk of preterm birth between 24 and 34 weeks' gestation. Prelabour caesareans were excluded for 'partograph used'.

For each ENC-related variable, the percentage use was calculated (mean, 95\% CI) according to variables relating to the health facility structure and the mothers' sociodemographic characteristics. Simple regression models were used to estimate the associations between the dependent variable (non-use to each item of essential newborn care) and the independent variables listed above. Crude ORs with respective 95\% CI were then estimated. In sequence, by the backward method, multiple regression models were developed with each dependent variable and the independent variables that proved significant in the first analysis. Independent variables that proved significant (to a 5\% level of significance) in explaining the use or the non-use of each of the essential care items were retained in the model. The ORs were adjusted, and the $95 \% \mathrm{CI}$ were estimated. All inferential analyses were weighted and took the sampling design plan into account, which considers the stratification, the conglomerate and the probability of the individuals. The results were obtained using IBM SPSS (Statistical Package for the Social Sciences, for Windows, V.22).

All hospital directors and postnatal women gave written informed consent.

\section{Patient involvement}

No patients were involved in defining the research question or the outcome measures, nor were they involved in the design and implementation of the study. There are no plans to involve patients in the dissemination of the results.

\section{RESULTS}

The coverage of the ENC items investigated according to location, type of funding, health facility structural variables and the mothers' characteristics is shown in table 1 . In Brazil, pregnant women were referred to a specific health facility during the antenatal period in $58.7 \%$ (95\% CI $56.7 \%$ to $60.7 \%$ ) of cases. According to the type of funding, this was higher in privately funded and for women with adequate antenatal care. Antenatal corticosteroids were used in $41.0 \%$ (95\% CI $34.2 \%$ to $48.0 \%$ ) of indicated pregnant women; it was less frequently used in publicly funded facilities, in the North and Mid-West regions, in facilities without paediatrician available 24 hours a day, with material resources $<80 \%$ and without a NICU. Partograph labour monitoring occurred in $48.5 \%$ (95\% CI $43.8 \%$ to $53.1 \%$ ) of the deliveries around 


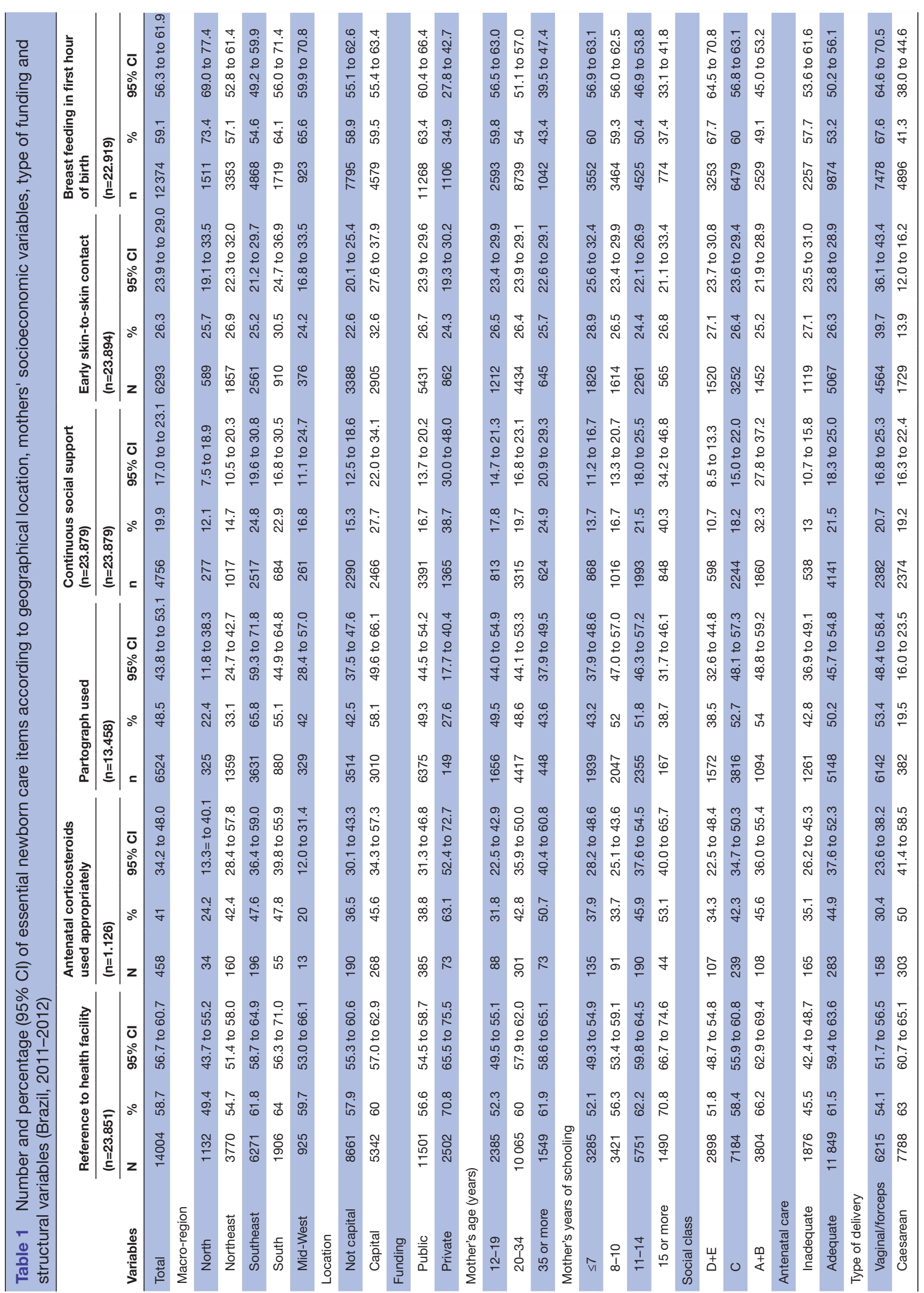




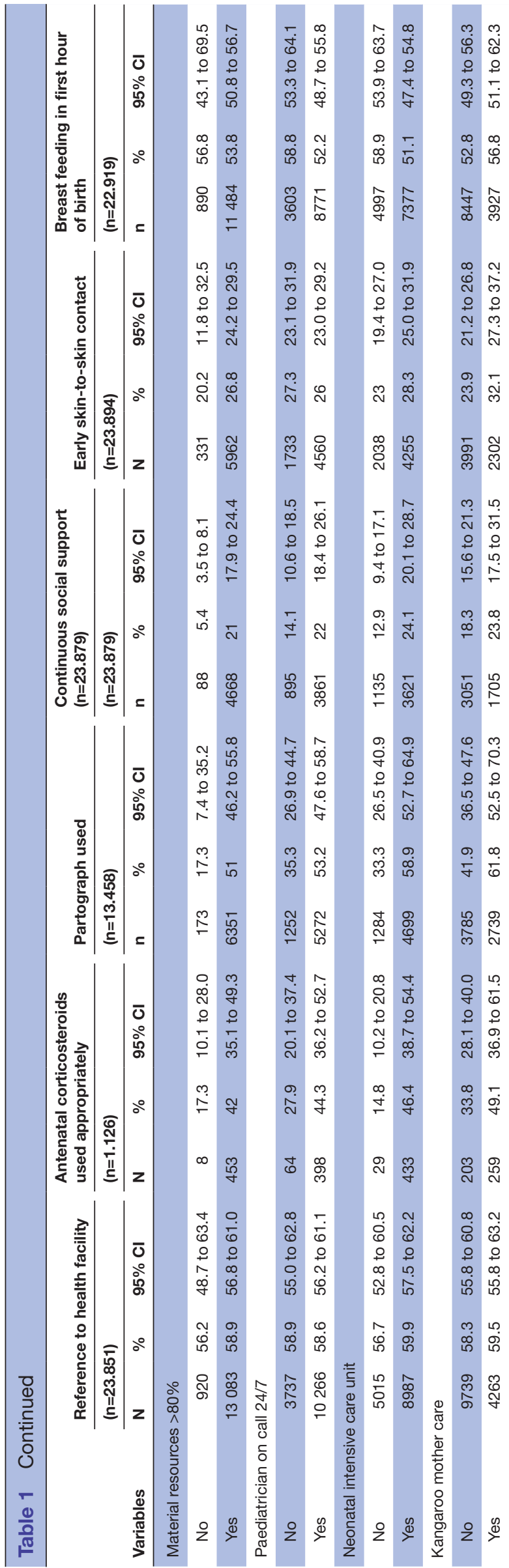

the country, with a distribution similar to antenatal corticosteroid use. Continuous social support during the hospital stay was provided to $19.9 \%$ (95\% CI $17.0 \%$ to $23.1 \%$ ) of the entire sample; it was higher in cases where the mother had 15 or more years of schooling, in facilities with a NICU, with material resources $>80 \%$, and with paediatrician available 24 hours a day. Early skin-to-skin contact occurred in $26.3 \%$ (95\% CI $23.9 .0 \%$ to $29.0 \%$ ) of cases and only in $13.9 \%$ (95\% CI $12.0 \%$ to $16.2 \%$ ) of women undergoing caesarean section. The rate of breast feeding in the first hour after birth was $59.1 \%$ (95\% CI 56.3 to 61.9 ); this was lower in privately funded facilities, for older women, for women with higher schooling and income and for women delivering by caesarean section.

The simple regression analysis (tables 2 and 3) identified health facilities with inadequate material resources (OR 3.46; 95\% CI 1.76 to 6.82) and an absence of NICU beds (OR 5.0; 95\% CI 2.97 to 8.43) as risk factors to the non-use of antenatal corticosteroids. Pregnant women in lower social classes were more likely to not receive continuous social support (social classes D+E: OR 4.0; $95 \%$ CI 2.96 to 5.41 ).

The adjusted logistic regression analysis (table 4) showed that privately funded women were more likely to not use a partograph $\left(\mathrm{OR}_{\mathrm{adj}} 3.36 ; 95 \%\right.$ CI 1.75 to 6.49$)$ and to not breast feed in the first hour after birth $\left(\mathrm{OR}_{\text {adj }}\right.$ $1.87 ; 95 \%$ CI 1.28 to 2.74$)$. The use of a partograph varies according to the region of residence; it is lower in the North $\left(\mathrm{OR}_{\text {adj }} 6.94 ; 95 \%\right.$ CI 2.89 to 16.82), Northeast $\left(\mathrm{OR}_{\text {adj }} 3.58 ; 95 \%\right.$ CI 2.15 to 5.95$)$ and Mid-West $\left(\mathrm{OR}_{\text {adj }}\right.$ 2.82; $95 \%$ CI 1.52 to 5.22 ).

Lower social class was related to lower continuous social support (social class C: $\mathrm{OR}_{\mathrm{adj}} 1.40 ; 95 \%$ CI 1.19 to 1.65 ; social class $\mathrm{D}$ and $\mathrm{E}: \mathrm{OR}_{\mathrm{adj}} 1.77 ; 95 \%$ CI 1.28 to 2.44$)$.

Caesarean section was associated with an absence of early skin-to-skin contact $\left(\mathrm{OR}_{\mathrm{adj}} 3.07 ; 95 \%\right.$ CI 3.37 to 4.90$)$ and breast feeding in first hour after birth $\left(\mathrm{OR}_{\mathrm{adj}} 2.55\right.$; 95\% CI 2.21 to 2.96), regardless of the maternal characteristics and the hospital structure.

\section{DISCUSSION}

In Brazil, neonatal morbidity and mortality remains high despite the availability of universal antenatal care and hospital delivery, highlighting the low quality in delivery and birth assistance. A widespread use of ENC items can effectively contribute to improving this situation.

However, our study has confirmed that the coverage of the ENC items in Brazil is low and that it varies, depending on the characteristics of both the mother and the health facility, where the delivery occurs.

The requirement for pregnant women to be enrolled with a referral health facility during the antenatal period has been regulated in Brazil since 2007. ${ }^{18}$ However, the percentage of pregnant women informed of the referral maternity, where they will be admitted to give birth, is still small. Pregnant women in labour may have to visit more than one hospital in order to be admitted for delivery 


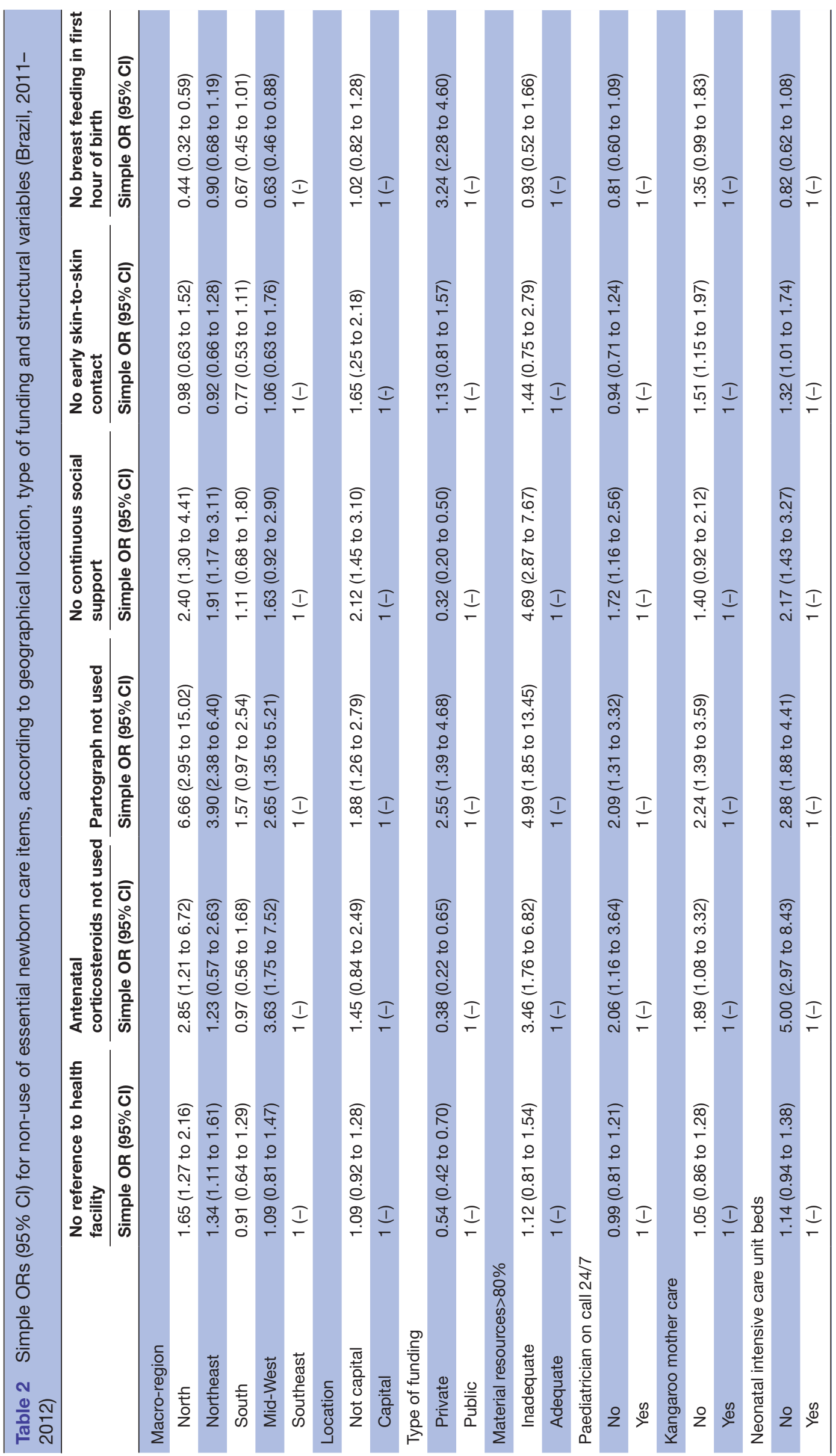




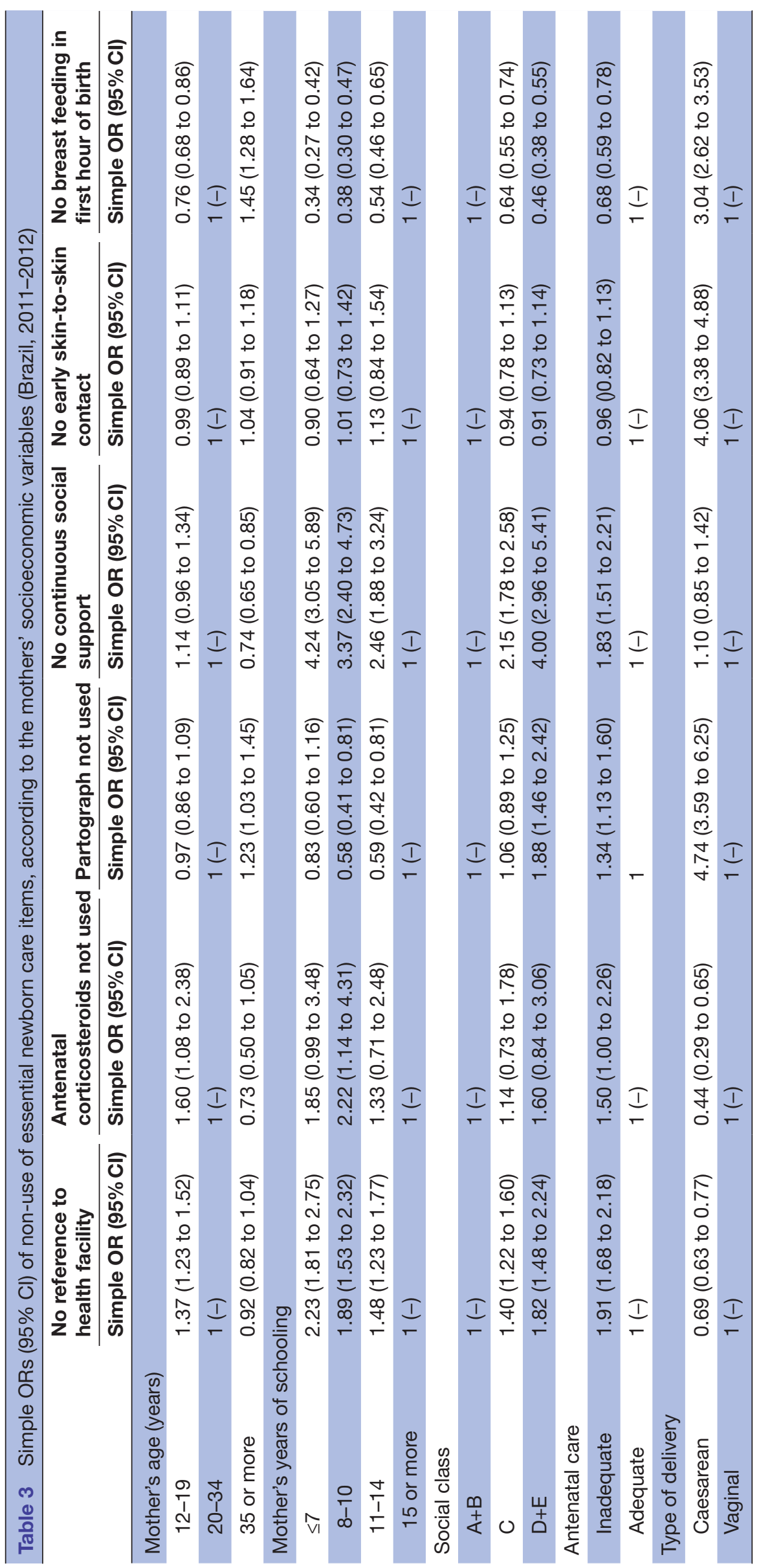


and this may contribute to the fact that only $10 \%$ of high-risk births occur in public maternities considered adequate for neonatal care in Brazil. This situation was highlighted by a prior study using data from the 'Birth in Brazil' survey. ${ }^{19}$ Such situations certainly put the health of women at risk, in addition to increasing the likelihood of neonatal death, ${ }^{7}$ and point to a failure in the integration between antenatal services and childbirth care.

Antenatal corticosteroids were used in only $41 \%$ of indicated cases and is another marked deficiency in the quality of antenatal care offered in Brazil. Every year, thousands of preterm babies are exposed to neonatal respiratory distress syndrome and to the risk of death from causes considered preventable if women received adequate care during pregnancy. ${ }^{1420}$ Corticosteroid use can avert $20 \%-40 \%$ of neonatal deaths related to complications from preterm birth. ${ }^{21}$ The fact that hospitals with private funding were more likely to use antenatal corticosteroids could be explained by mothers having greater access to antenatal care and by a more formal link between antenatal and childbirth care compared with publicly funded hospitals. The rate of corticosteroid antenatal use in our study was lower than those previously reported in other countries, for example, Japan $(58 \%)$, Peru $(75 \%)^{22}$ and the USA $(87 \%) .{ }^{23}$ Intensive efforts are needed to scale up the use of antenatal corticosteroids in facilities across Brazil.

It is estimated that the use of a partograph can reduce early neonatal deaths from asphyxia by $40 \% .{ }^{21}$ We found the use of partographs is still very far from the recommended level of $90 \% .^{21}$ Worryingly, women who underwent caesarean delivery were less likely to have been monitored during labour and were consequently more likely to suffer undesirable maternal and/or neonatal outcomes. We found that births in privately funded facilities were a risk factor for not using a partograph, probably due to the fact that prelabour caesarean section is frequent $(78.3 \%)$ in those facilities. ${ }^{24}$

In Brazil, all women are entitled to a companion during their hospital stay for delivery. ${ }^{25}$ However, this item had the lowest coverage $(<20 \%)$. A previous study, ${ }^{26}$ based on the 'Birth in Brazil' project and focussing on the implementation of the requirement of continuous social support during hospital stays for childbirth, found that the main reason for not having a companion present during delivery was due to prohibition by the hospital and that only $1.4 \%$ of women did not wish to be accompanied. Our results demonstrate the positive effect of adequate structures at facilities on ECN practices. These facilities have probably more physical capacity and material resources to support a companion.

The coverage of early skin-to-skin contact in Brazil is lower than in Argentina (83\%), similar to Nagpur $(32 \%)$ and Kenya $(25.1 \%)$, and is higher than Pakistan $(2 \%) .{ }^{27}$ In the USA, early skin-to-skin rates were $83 \%$ in vaginal deliveries and $69.9 \%$ in uncomplicated caesarean births. ${ }^{28}$ Our results show that in health facilities in capital cities, newborns by vaginal delivery were more likely to 
experience skin-to-skin contact and protection from hypothermia, which reduces the risk of infection, coagulation disorders, neonatal respiratory distress syndrome and cerebroventricular haemorrhage, directly influencing neonatal mortality and morbidity. ${ }^{29}$ It is estimated that proper prevention and management of hypothermia could avert $40 \%$ of neonatal mortality. ${ }^{30}$

Early breast feeding within the first hour of birth is an important factor associated with lower neonatal mortality, ${ }^{31}$ averting around $10 \%$ of neonatal deaths. ${ }^{30}$ This study found the coverage to be around $59 \%$ in Brazil, which is slightly higher than the mean of $50 \%$ found by Requejo et a $\vec{l}^{3}$ for the 75 countries responsible for $95 \%$ of all neonatal deaths. The coverage in Brazil is classified as good according to WHO, ${ }^{32}$ lower than the coverage in Zambia $(92 \%)^{27}$ and higher than in India (36.4\%), Bangladesh (24\%) or Pakistan $(8.5 \%){ }^{33}$

A study in India, ${ }^{34}$ examining over 12000 births after training in the ENC programme, reported that the coverage of breast feeding in the first hour after birth increased from $73.1 \%$ to $88.4 \%$ and early skin-to-skin contact increased from $50.2 \%$ to $81.7 \%$, while neonatal mortality decreased.

Our results demonstrate the negative effect of caesarean sections on early breast feeding. Data from a meta-analysis, ${ }^{35}$ covering more than half a million women in 31 countries, suggested an inverse association between caesarean delivery and early breast feeding, corroborating the association found in this study. This fact may be related to anaesthesia and postpartum surgical procedures. ${ }^{36}$ As the frequency of caesarean delivery in Brazil has reached high levels of around $56 \%,{ }^{6}$ the situation calls for interventions to evaluate more judiciously the options available for this kind of delivery. In Brazil, it was verified that caesarean section was associated with the birth of preterm and early term babies and these babies are more likely to be admitted to NICU, hindering early lactation. ${ }^{37} 38$ To reduce neonatal mortality in Brazil, all mothers, regardless of mode of delivery, should be encouraged to breastfeed early. Caesarean delivery can delay the onset of lactation, disrupt mother-infant interaction or inhibit infant suckling. ${ }^{35}$ Lassi et al describe a $44 \%$ reduction in neonatal mortality when breast feeding began in the first 24 hours after birth. ${ }^{39}$ In another study of $>10000$ newborns in Brazil, ${ }^{36}$ the delivery location was described as a pivotal factor for breast feeding, which was not found in this study.

\section{LIMITATIONS}

The 'Birth in Brazil' study was conducted in hospitals with $>500$ deliveries per year and $80 \%$ of childbirths in the country are in these hospitals. Smaller hospitals are likely to have worse structures, which would result in an underestimation of the inadequacies of healthcare. The study data were based on information provided by women early after delivery, by managers and from medical records, rather than from observation of the performance of the essential care items. This study was not originally designed to examine the ENC and thus did not include all the items of the programme. Nonetheless, the items investigated here are described worldwide as evidencebased cost-effective interventions in reducing neonatal mortality and morbidity. ${ }^{21} 39$

\section{CONCLUSION AND RECOMMENDATIONS}

We found a positive effect of adequate structure at health facilities on the use of antenatal corticosteroids and partographs during labour. We found a negative effect of caesarean section on early skin-to-skin contact and early breast feeding.

In Brazil, the South and Southeast regions have the lowest rate of neonatal mortality ${ }^{7}$ and these regions have more reference hospitals for the care of high-risk pregnancies and neonates. ${ }^{13}$ The North and Northeast regions have the highest rate of neonatal mortality, ${ }^{7}$ have fewer reference hospitals, ${ }^{13}$ have less access to antenatal care services and, in these regions, the majority of hospitals are located in state capitals. ${ }^{40}$ The regional differences, as observed in other countries, ${ }^{41}$ reveal inequalities in the distribution of health funding and exemplify the phenomenon described as the Inverse Care Law, ${ }^{42}$ where individuals with fewer financial resources and with greater need receive worse and lower quality healthcare.

The essential interventions investigated here are simple and inexpensive and should be integrated into existing health policies. The low and uneven coverage of such simple health technologies indicates the necessity for more widespread interventions to improve perinatal outcomes. Related coverage data should also be collected frequently in routine national surveys to guide the allocation of funding in priority areas, such as health facilities without NICU and with inadequate material resources.

Acknowledgements The authors would like to thank The Scientific Editing Company, UK for professionally editing the paper. The authors would like to thank the regional and state coordinators, supervisors, data collectors and all the staff at the participating health facilities from the 'Birth in Brazil' study. The authors would also like to thank the mothers who participated and made this study possible.

Contributors MASM, RG, RC and SDAB participated in the design, analysis, data interpretation and in the drafting and final approval of the manuscript; VEP collaborated in the database organisation and statistical analysis; MCL participated in the design of the article, oversaw the analysis and made the final revision of the article. All coauthors contributed to the improvement of the article.

Funding This work was supported by the Ministério da Ciência, Tecnologia e Inovação - Conselho Nacional de Desenvolvimento Científico e Tecnológico; Fundação Carlos Chagas Filho de Amparo à Pesquisa do Estado do Rio de Janeiro and Fundação Oswaldo Cruz.

Disclaimer The funders had no role in the study design, data collection and analysis, decision to publish or preparation of the manuscript.

Competing interests None declared.

Patient consent for publication Obtained.

Ethics approval The ethics committee of the Sergio Arouca National School of Public Health, 0swaldo Cruz Foundation (CEP/ENSP), approved this study under the research protocol CAAE: 0096.0.031.000-10.

Provenance and peer review Not commissioned; externally peer reviewed.

Data sharing statement Participant data will not be shared. 
Open access This is an open access article distributed in accordance with the Creative Commons Attribution Non Commercial (CC BY-NC 4.0) license, which permits others to distribute, remix, adapt, build upon this work non-commercially, and license their derivative works on different terms, provided the original work is properly cited, appropriate credit is given, any changes made indicated, and the use is non-commercial. See: http://creativecommons.org/licenses/by-nc/4.0/.

\section{REFERENCES}

1. Nations U. Sustainable Development. 2017 https://sustainabledevel opment.un.org/sdg3

2. UNICEF. Committing to child survival : a promise renewed. progress report. 2014;104 WwwApromiserenewedOrg.

3. Requejo JH, Bryce J, Barros AJ, et al. Countdown to 2015 and beyond: fulfilling the health agenda for women and children. Lancet 2015;385:466-76.

4. Bhutta ZA, Das JK, Bahl R, et al. Can available interventions end preventable deaths in mothers, newborn babies, and stillbirths, and at what cost? Lancet 2014:384:347-70.

5. Narayanan I, Rose M, Cordero D, et al. The Components of Essential Newborn Care. United States Agency Int Dev: Basics Support Institutionalizing Child Surviv Proj (BASICS II), 2004.

6. Leal MDC, Szwarcwald CL, Almeida PVB, et al. Reproductive, maternal, neonatal and child health in the 30 years since the creation of the Unified Health System (SUS). Ciência e Saúde Coletiva 2018;23:1915-28.

7. Lansky S, Friche AA, de L, et al. Birth in Brazil survey : neonatal mortality profile, and maternal and child care. Cad Saúde Pública 2014;30:192-207.

8. Black RE, Cousens S, Johnson HL, et al. Global, regional, and national causes of child mortality in 2008: a systematic analysis. Lancet 2010;375:1969-87.

9. You D, Hug L, Ejdemyr S, et al; World. child mortality. : UNICEF WHO World Bank Gr United Nations, 2015:2015: 74. www.childmortality. org.

10. do Carmo Leal M, da Silva AA, Dias MA, et al. Birth in Brazil: national survey into labour and birth. Reprod Health 2012;9:15.

11. Vasconcellos MT, Silva PL, Pereira AP, et al. Sampling design for the birth in brazil: national survey into labor and birth. Cad Saude Publica 2014;30:S49-58.

12. HALDANE JB. On a method of estimating frequencies. Biometrika 1945;33:222-5.

13. Azevedo Bittencourt SD, Costa Reis LG, Ramos MM, et al. Structure in Brazilian maternity hospitals: key characteristics for quality of obstetric and neonatal care. Cad Saude Publica 2014;30:S1-12.

14. Roberts D, Brown J, Medley N, et al. Antenatal corticosteroids for accelerating fetal lung maturation for women at risk of preterm birth. Cochrane Database Syst Rev 2017;180.

15. Pereira AP, Leal MC, da Gama SG, et al. Determining gestational age based on information from the Birth in Brazil study. Cad Saude Publica 2014;30:S1-12.

16. Saúde M. Portaria $\mathrm{n}^{\circ} 1071$, de 04 de julho de 2005 . Institui a política nacional de atenção ao paciente crítico diário of da união. 2005.

17. ABEP. Brazilian Criteria 2015 and social class distribution update for 2016. 2016:1-6 www.abep.org

18. BRASIL. Lei $n^{\circ} 11.634$, de 27 de dezembro de 2007 Dispõe sobre o direito da gestante ao conhecimento e a vinculação à maternidade onde receberá assistência, no âmbito do Sistema Único de SaúdeSUS. 2007.

19. de Azevedo Bittencourt SD, Queiroz Gurgel R, da Silva Menezes MA, et al. Neonatal care in Brazil: hospital structure and adequacy according to newborn obstetric risk. Paediatr Int Child Health 2015;35:206-12.

20. Malta DC, França E, De ADX, et al. Update of avoidable causes of death due to interventions at the Brazilian Health System. Epidemiol e Serviços Saúde 2010;20:409-12.
21. Darmstadt GL, Bhutta ZA, Cousens S, et al. Evidence-based, costeffective interventions: how many newborn babies can we save? Lancet 2005;365:977-88.

22. Vogel JP, Souza JP, Gülmezoglu AM, et al. Use of antenatal corticosteroids and tocolytic drugs in preterm births in 29 countries: an analysis of the WHO Multicountry Survey on Maternal and Newborn Health. Lancet 2014;384:1869-77.

23. Stoll BJ, Hansen NI, Bell EF, et al. Trends in care practices, morbidity, and mortality of extremely preterm neonates, 1993-2012. JAMA 2015;314:1039-51.

24. Domingues RM, Dias MA, Nakamura-Pereira M, et al. Process of decision-making regarding the mode of birth in Brazil: from the initial preference of women to the final mode of birth. Cad Saude Publica 2014;30:1-16.

25. Brasil. Lei $n^{\circ} 11.108$, de 07 de abril de 2005. Dispõe sobre o direito da parturiente à presença de acompanhante durante o trabalho de parto, parto e pós-parto imediato, no âmbito do Sistema Único de Saúde-SUS Diário Of da União. 2005.

26. Diniz CS, d'Orsi E, Domingues RM, et al. Implementation of the presence of companions during hospital admission for childbirth: data from the birth in brazil national survey. Cad Saude Publica 2014;30:S140-53.

27. Dhaded SM, Somannavar MS, Vernekar SS, et al. Neonatal mortality and coverage of essential newborn interventions 2010 - 2013: a prospective, population-based study from low-middle income countries. Reprod Health 2015;12:S6.

28. Prevention C for DC and. Breastfeeding. Report Card. 2015 https:// www.cdc.gov/breastfeeding/data/mpinc/data/2015/tables2_1a-2_4a. $\mathrm{htm}$

29. Lyu Y, Shah PS, Ye XY, et al. Canadian Neonatal Network. Association between admission temperature and mortality and major morbidity in preterm infants born at fewer than 33 weeks' gestation. JAMA Pediatr 2015;169:e150277.

30. Darmstadt GL, Walker N, Lawn JE, et al. Saving newborn lives in Asia and Africa: cost and impact of phased scale-up of interventions within the continuum of care. Health Policy Plan 2008;23:101-17.

31. Khan J, Vesel L, Bahl R, et al. Timing of breastfeeding initiation and exclusivity of breastfeeding during the first month of life: effects on neonatal mortality and morbidity-a systematic review and metaanalysis. Matern Child Health J 2015;19:468-79.

32. WHO (World Health Organization), UNICEF (United Nations Children's Fund). Global strategy for infant and young child feeding. World Heal Organ 2003:1-30.

33. Adhikari M, Khanal V, Karkee R, et al. Factors associated with early initiation of breastfeeding among nepalese mothers: further analysis of nepal demographic and health survey, 2011. Int Breastfeed $J$ 2014:9:21.

34. Goudar SS, Dhaded SM, McClure EM, et al. ENC training reduces perinatal mortality in Karnataka, India. J Matern Fetal Neonatal Med 2012;25:568-74.

35. Prior E, Santhakumaran S, Gale C, et al. Breastfeeding after cesarean delivery: a systematic review and meta-analysis of world literature. Am J Clin Nutr 2012;95:1113-35.

36. Boccolini CS, Carvalho ML, Oliveira MI, et al. Factors associated with breastfeeding in the first hour of life. Rev Saude Publica 2011;45:69-78.

37. Leal MDC, Esteves-Pereira AP, Nakamura-Pereira M, et al. Burden of early-term birth on adverse infant outcomes: a population-based cohort study in Brazil. BMJ Open 2017;7:e017789.

38. Leal M, Esteves-Pereira AP, Nakamura-Pereira M, et al. Prevalence and risk factors related to preterm birth in Brazil. Reprod Health 2016;13.

39. Lassi ZS, Middleton PF, Crowther C, et al. Interventions to improve neonatal health and later survival: an overview of systematic reviews. EBioMedicine 2015;2:985-1000.

40. Viellas EF, Domingues RM, Dias MA, et al. Prenatal care in Brazil. Cad Saude Publica 2014;30 :S15-1.

41. Lassi ZS, Salam RA, Das JK, et al. Essential interventions for maternal, newborn and child health: background and methodology. Reprod Health 2014;11:S1.

42. Tudor Hart J. The inverse care law. The Lancet 1971;297:405-12. 